AIAA 2001-5002

\title{
SCIENCE OF DETACHED BRIDGMAN GROWTH AND SOLUTOCAPILLARY CONVECTION IN SOLID SOLUTION CRYSTALS
}

\author{
F.R. Szofran \\ Member, Scientist, Biological and Physical Space Research Laboratory \\ NASA Marshall Space Flight Center, Huntsville, AL 35812 USA \\ M.P. Volz, S.D. Cobb \\ Scientist, Biological and Physical Space Research Laboratory \\ NASA Marshall Space Flight Center, Huntsville, AL 35812 USA \\ S. Motakef \\ President, Cape Simulations, Inc., Newton, MA 02158 USA \\ A. Cröll \\ Professor, Institut für NE-Metallurgie und Reinststoffe, University of Freiberg, D-09599 Freiberg, Germany \\ P. Dold \\ Scientist, Kristallographisches Institut, University of Freiburg, D-79104 Freiburg, Germany
}

\section{ABSTRACT}

Bridgman and float-zone crystal growth experiments are planned for NASA's Materials Science Research Rack using the European Space Agency's Materials Science Laboratory with the Low Gradient Eurnace (LGF) and Float Zone Furnace with Rotating Magnetic Field (FMF) inserts, respectively. Samples will include $\mathrm{Ge}$ and $\mathrm{Ge}-\mathrm{Si}$ alloys with up to $10 \mathrm{at} \%$ $\mathrm{Si}$. The planned experiments in microgravity will provide information unattainable from Earth-based experiments. The Bridgman part of the investigation includes detached growth samples and microgravity will enhance the ability to study the science of detachment. Repeatable Earth-based experiments show promise that the method can be perfected for terrestrial use. This capability would greatly improve the crystalline quality of selected materials of substantial technological interest because it would eliminate contact between the solidified crystal and the container wall. For float-zone growth, microgravity experiments are the only way to separate the segregation contributions of soluto- and thermocapillary convection from buoyancy-driven convection. Thus, solutocapillary convection is frequently ignored or poorly estimated in modeling float-zone growth of alloys. Additionally, the size limitation of the zone height (and crystal diameter) of about $10 \mathrm{~mm}$ under Earth conditions is only limited in space by the heater power and furnace geometry. Larger zones increase the accessible range of convection strength and thus enable the determination of critical values for convection.

\section{INTRODUCTION}

\section{Experiment Team}

This investigation is an international collaboration with two universities in Germany and the Marshall Space Flight Center (MSFC) along with one U.S. university and a small business enterprise. To reach the objectives of the investigation, flight experiments involving Bridgman crystal growth and float-zone crystal growth must be completed. In terms of

This material is declared a work of the U.S. Government and is not subject to copyright protection in the United States. planning, cooperation, and sharing of information, the U.S. and German teams participate fully and equally in all aspects. Electronic and verbal communication between the investigation teams is open and frequent; there have been numerous visits, including extended stays, between the teams. With respect to resources, the German and U.S. investigations are independent and parallel. To minimize duplication of effort and to take best advantage of available resources including personnel and equipment, the Bridgman part of the investigation is being led by the U.S. team and the float-zone part of the investigation is being led by the German team funded by the German Space Agency, 